\title{
Ayah dan Pendidikan Karakter Anak (Kajian Teks dan Konteks Perspektif Psikologi Pendidikan Islam)
}

\author{
${ }^{1}$ Fitriah M. Suud, ${ }^{2}$ Aulia Rahmi, ${ }^{3}$ Fadhilah \\ ${ }^{1}$ Universitas Muhammadiyah Yogyakarta, ${ }^{2,3}$ Universitas Serambi Mekkah \\ Email: fitriahmsuud@gmail.com
}

\begin{abstract}
The quality and quantity of mother and child attachment have often been discussing. Nevertheless, how the quality and quantity of the relationship between father and son, especially in shaping the child's personality is still rarely found. In the life of a child, sometimes role, the father is not felt because his figure is busy outside the home. Also provides an assumption that the father does not influence raising and educating children. The context of Islamic education in the family, the figure of the father, is the spiritual basis that underlies the role of parents in educating their children. A person's character formed early on. In this case, the role of the family is indeed very influential. The education of the father in the family is critical and is a fundamental pillar of character building for a child. From a child's father learns, hardened, brave, responsible, and easy to get along with the outside world. This study aims to present the role of fathers in shaping the character of children in terms of the study of texts and contexts through the field of psychology in Islamic education. The contextual study presents the latest research that proves the influence of the father in many ways for children and terms of the text of this study will present the primary sources of guidance for Muslim life, namely the Qur'an and the Hadith. So the implications given are not only normative but grounded to be able to broaden understanding and add new constructs for the implementation of the father and son relationship.
\end{abstract}

Keywords: Father, Character, Child, Psychology of Islamic Education, Text and Context

\section{Pendahuluan}

Peran ayah dalam kehidupan kehidupan anak, tidak terlalu terasa disebabkan karena sosoknya lebih banyak menghabiskan waktu di luar rumah. Sehingga hal ini menimbulkan anggapan bahwa ayah tidak memiliki pengaruh besar dalam membesarkan dan mendidik anak. Sementara sosok ibu begitu melekat dengan sang anak karena sejak dalam kandungan, melahirkan hingga menemani masa kecilnya secara normal ibu selalu ada bersama anak. Bahkan sebuah penelitian menyebutkan bahwa Persepsi ayah tentang memberi makan anak-anakpun jarang dipertimbangkan dalam literatur. ${ }^{1}$ Namun sebenarnya setelah ditelusuri dari penelitian ternyata ayah memiliki peran yang besar. Demikan pula jika kembali pada sumber pedoman utama ajaran Islam bahwa sosok ayahlah yang menjadi dasar spiritual yang mendasari peran orang tua dalam mendidik anak-anaknya.

Allah SWT dalam surah at-Tahrim:6 menyampaikan seruan kepada orang-orang beriman agar menjaga diri dan keluarga dari api neraka. Ayat ini dikhususkan kepada seorang ayah sebagai kepala keluarga agar melindungi dirinya dan keluarganya (istri dan anak-anaknya) dari segala sesuatu yang menjerumuskan kehidupan, segala sesuatu yang akan menyengsarakan kehidupan mereka. Sehingga ayat di atas jelas bahwa sosok

${ }^{1}$ Holly A. Harris, Elena Jansen, Tony Rossi, 'It's not worth the fight': Fathers' perceptions of family mealtime interactions, feeding practices and child eating behaviours, Appetite, Volume 150, 2020,104642, ISSN 0195-6663, https://doi.org/10.1016/j.appet.2020.104642. 
seorang ayah bukan hanya sebagai pencari nafkah tetapi harus menjadi pendidik bagi anak-anaknya apalagi saat usia anak berada pada usia dini yang merupakan masa pembentukan karakter anak sehingga harus diperhatikan dengan sebaik dan semaksimal mungkin.

Pendidikan seorang ayah dalam keluarga sangatlah penting dan merupakan pilar pokok pembangunan karakter seorang anak. Dari ayah seorang anak belajar, tangguh, berani, bertanggung jawab, dan mudah bergaul dengan dunia luar. Dalam Alquran terdapat 17 dialog yang mengajarkan mengenai pengasuhan anak yang terdiri atas 14 dialog ayah-anak; 2 dialog ibu-anak; 1 dialog guru-murid. Itu menunjukkan peran ayah dalam pengajaran anak-anaknya melebihi ibu dan guru. Dari sisi sirah menunjukkan bahwa pendidikan Rasulullah dibina oleh kakek dan pamannya (sosok ayah). Dalam kisah al-Qur'an juga diitemukan bagaimana sosok ayah seorang Nabi Ibrahim, begitu juga dengan Luqman, Nabi Ya'qub dan Nabi Nuh. Dengan demikian, sosok ayah adalah sosok yang sangat krusial dalam perkembangan anak. Harus ada sosok ayah (laki-laki) dalam pengasuhan anak.

Kisah Nabi Ibrahim dengan putranya terekam dalam alQur'an surat as-saffat ayat 100 samapai dengan ayt 102 . Dialog mereka kemudian menjadi banyak rujukan bagaimana membangun komunikasi, kasih saying sopan dan bagaimana memebntuk ta'zhimnya seorang pada pada orangtuanya. Dalam surat al-Baqarah ayat ke 132 kisah Ibrahim diulang kembali untuk mnegingatkan pada ummat untuk mengambil ibrah dari kisahnya mendidik anak. Ayat ini juga menegaskan contoh yang dapat ditelusuri untuk dipelajari adalah bagaimana kisah Ya'qub dengan anaknya. Untuk lebih jelasnya tentang kisah Ya'qub dan anaknya, Allah SWT menceritakan bagaimanna kisah komunikasi dan pengasuhan dalam surah Yusuf.

Kisah lain terekam dengan baik dan jelas tentang bagaimana seharusnya ukhwah ayah dan anak itu dibangun. Al-Qur'an surah Luqman di ayat ke 13 memberikan gambaran bagaimana sikap dan kata-kata yang dipilih seorang ayah dalam memberikan pesan kepada anaknya dan pesan apa yang paling utama untuk disampaikan. Panggilan ayah terhadap anak dalam kisah ini menunjukkan bahwa hal ini penting untuk diperhatikan dan ternyata secara psikologis panggilan saying dan perhatiannya dapat menumbuhkan kelekatan yang lebih antara orang dan anak. Selanjutnya ucapan wahai anakku tersirat makna pengakuan pada ia adalah anaknya ikut memberika efek positif yang menyentuh sensitivitas seorang anak yang membuat ia semakin terikat dengan orang tuanya.

Tidak cukup dengan kisah Ibrahim, Yusuf dan Lukman, peristiwa Nuh dengan anaknya kembali diabadikan dalam surah Hud. Cinta kasih ayah dan anak terekam dalam ayat 42 dan 43, ketiga Nuh memanggil anaknya untuk ikut bersamanya dalam kapal disaat air bah akan naik dan menenggelamkan tempat itu. Upaya seorang menyelamatkan anaknya, panggilan penuh kasih dan perhatian serta tanggujawabnya jelas tersirat dalam ayat ini. Selanjutnya kisah Nuh dengan anak dan keluarganya menjadi pedoman bagaimana upaya dan usaha ayah mengajak keluarganya agar selamat dari musibah.

Kisah-kisah sosok ayah dan anak dalam ayat-ayat tersebut dapat menjadi pedoman dan ibrah bagi semua bahwa ayah sangat memiliki peran bahkan memiliki peran utama 
dalam membentuk karakter anak. Namun lagi-lagi kisah ini harus dikaji dengan kkacamata kontekstual karena zaman semakin berubah. Membacanya tidak hanya cukup dengan terjemahan atau bahkan dengan tafsiran saja namun kajian ini harus difahami lebih mendalam dengan melihat dari berbagai disiplin ilmu. Jika Nuh ingin menyelamatkan anaknya dari air bah, bagaimana saat ini air bah itu ada dalam banyak media elektornik, dunia maya yang membuat seorang anak tenggelam dalam kelalaian dan lupa tujuan hidup. Sehingga membaca teks perlu dibarengi dengan konteks. Sehingga tulisan ini menyajikan keduanya untuk melihat dan menemukan keterpaduan kajian teks dan konteks sehingga ajaran normative tidak melangit tetapi dapat membumi berkajian-kajian kontekstual.

\section{Pembahasan}

\section{A. Literature Review}

Sebuah penelitian deskriptif kualitatif dilakukan untuk mengeksplorasi pengalaman ayah yang anak-anak memiliki cacat jantung bawaan yang parah di Korea. Penelitian ini menemukan bahwa ayah memiliki penderitaan yang memilukan, merasakan pengendalian diri yang hebat dalam menghadapi kenyataan anaknya, dan menyeimbangkan kondisi kehidupan anaknya. Sehingga kesimpulan dari penelitian ini adalah tekanan psikologis ayah yang cukup mirip dengan ibu selama berminggu-minggu hingga berbulan-bulan setelah diagnosis. Hasilnya juga menggambarkan strategi koping, pengalaman ayah dan peran pengasuhannya dalam membesarkan anak-anak mereka. ${ }^{2}$

Kurangnya perhatian ayah ternyata memberikan dampak keterlibatan ayah pada perempuan remaja kulit hitam. Penelitian Dorsey ini dilakukan terhadap para remaja putri yang terlibat dalam kenakalan remaja dan yang sering terlibat dengan penegak hukum. Hasil menunjukkan bahwa di antara remaja perempuan kulit hitam dengan angka ayah biologis, prediktor signifikan dari niat mereka untuk terlibat dalam perilaku berisiko dipengaruhi oleh perhatian ayah yang minim. Namun penelitian ini menunjukkan bahwa dimensi keterlibatan ayah ini tidak signifikan untuk remaja yang tinggal di rumah tangga dengan ayah sosial. ${ }^{3}$

Ayah memainkan peran penting dalam perkembangan sosial-emosional dan kognitif anak. ${ }^{4}$ Sethna menyelidiki hubungan antara interaksi Antara ayah dengan bayi. Khususnya sensitivitas ayah, dan volume otak regional dalam sampel komunitas dari bayi berusia 3 hingga 6 bulan. Studi ini memberikan bukti

2Ji-Hye Hwang, Sun-Mi Chae, Experiences of fathers of young children with severe congenital heart efects in Korea: A qualitative descriptive study, Journal of Pediatric Nursing, 2020, ISSN 0882-5963, https://doi.org/10.1016/j.pedn.2020.02.040.

${ }^{3}$ Qiana R. Cryer-Coupet, Marquitta S. Dorsey, Brianna P. Lemmons, Elan C. Hope, Examining multiple dimensions of father involvement as predictors of risk-taking intentions among black adolescent females, Children and Youth Services Review, Volume 108, 2020, 104604, ISSN 0190-7409, https://doi.org/10.1016/j.childyouth.2019.104604.

${ }^{4}$ Vaheshta Sethna, Jasmine Siew, Inês Pote, Siying Wang, Maria Gudbrandsen, Charlotte Lee, Emily Perry, Kerrie P.H. Adams, Clare Watson, Johanna Kangas, Vladimira Stoencheva, Eileen Daly, Maria Kuklisova-Murgasova, Steven C.R. Williams, Michael C. Craig, Declan G.M. Murphy, Grainne M. McAlonan,Father-infant interactions and infant regional brain volumes: A cross-sectional MRI study, Developmental Cognitive Neuroscience, Volume 40, 2019, 100721, ISSN 1878-9293, https://doi.org/10.1016/j.dcn.2019.100721 
terdapat hubungan interaksi ayah-anak dan variasi dalam anatomi otak bayi. Ada bukti kuat bahwa ayah memainkan peran penting dalam perkembangan anakanak ${ }^{5}$. Secara khusus, kualitas interaksi ayah-bayi secara independen berkontribusi pada berbagai hasil perkembangan pada anak. ${ }^{6}$ Misalnya, sensitivitas ayah dan keterlibatan pada masa bayi dan anak usia dini terkait dengan perkembangan kognitif dan bahasa yang lebih baik pada anak-anak mereka. ${ }^{7}$ Sebaliknya, pengasuhan ayah yang berkualitas buruk akan dapat berisiko membuat remaja terjebak pada prilaku terlarang. ${ }^{8}$ Penelitian lain juga dilakukan untuk melihat hubungan ayah dan anak. Uniknya penelitian ini menyorot tentang peran ayah dalam menyediakan makanan untuk anak. Walaupun interaksinya tidak seintens hubungan anak dan ibu tetapi perhatian ayah saat memenuhi kebutuhan pangan anak memberikan hubungan yang singnifakan terhadap perkembangan anak. ${ }^{9}$ Sehingga penelitian ini menyarankan supaya ayah dengan sepenuhnya bertanggungjawab menjalankan tugasnya dalam memenuhi kebutuhan keluarga khususnya anak-anak mereka.

Dalam banyak penelitian pun telah ditemukan kualitas hubungan orang tua-remaja telah terbukti mempengaruhi kesehatan mental remaja. Salah satunya adalah penelitiannya L. O'Gara ${ }^{10}$ Bahkan penilaiannya mulai mengkaji mengenai mekanisme di mana hubungan ayah-anak mempengaruhi kesehatan fisik remaja. Melalui analisis regresi linier peneliti menyelidiki apakah kesehatan mental remaja berusia 15 tahun, dioperasionalkan sebagai gejala kecemasan dan depresi, memediasi hubungan antara kedekatan yang dirasakan remaja dengan ayah dan kesehatan dalam penilaian diri. Temuannya bahwa kedekatan ayah dengan remaja secara langsung berkaitan dengan kesehatan dan bahwa hubungan lebih signifikan terdapat pada kesehatan mental remaja untuk anak laki-laki dan sebagian mempengaruhi kesehatan mental anak perempuan. Sehingga temuan tersebut memperluas pemahaman tentang hubungan ayah dan remaja mempengaruhi kesehatan dan kesejahteraan remaja.

Kajian tentang moral juga telah dilakukan oleh Wang dan rekannya. Ketiadaan perhatian pada nilai moral ayah dan ibu diperiksa sebagai dua moderator dari efek buruk pada masa kanak-kanak, remaja dan dapat

${ }^{5}$ N.J. Cabrera, H.E. Fitzgerald, R.H. Bradley, L. RoggmanThe ecology of father-child elationships: an expanded model J. Fam. Theory Rev., 6 (4) (2014), pp. 336-354

${ }^{6}$ B. Barker, J.E. Iles, P.G. RamchandaniFathers, fathering and child psychopathology Curr. Opin. Psychol., 15 (2017), pp. 87-92

${ }^{7}$ V. Sethna, E. Perry, J. Domoney, J. Iles, L. Psychogiou, N.E.L. Rowbotham, et al.Father-child interactions at 3 months and 24 months: contributions to children's cognitive development at 24 months Infant Ment. Health J., 38 (3) (2017), pp. 378-390

${ }^{8}$ R. Kok, P. Prinzie, M.J. Bakermans-Kranenburg, F.C. Verhulst, T. White, H. Tiemeier, et al.Socialization of prosocial behavior: gender differences in the mediating role of child brain volume Child Neuropsychol., 18 (10) (2018), pp. 1-11

${ }^{9}$ April Litchford, Mateja R. Savoie Roskos, Heidi Wengreen, Influence of fathers on the feeding practices and behaviors of children: A systematic review, Appetite, Volume 147, 2020, 104558, ISSN 0195-6663, https://doi.org/10.1016/j.appet.2019.104558.

10 Jaimie L. O'Gara, Anao Zhang, Yolanda Padilla, Chun Liu, Kaipeng Wang, Father-youth closeness and adolescent self-rated health: The mediating role of mental health, Children and Youth Services Review, Volume 104, 2019, 104386, ISSN 0190-7409, https://doi.org/10.1016/j.childyouth.2019.104386. 
menyebabkan mereka terjebak pada tindakan kejahatan cyber. Hasil penelitian ini juga menunjukkan bahwa remaja dengan penganiayaan masa kanak-kanak yang tinggi lebih mungkin untuk dibully dan membully. ${ }^{11}$ Kenakalan remaja seperti terjebak dalam hal berisiko lebih tinggi menggunakan narkoba juga dapat disebabkan oleh ketiadaan perhatian orang tua.

Penelitian berikutnya ini mengkaji bagaiman peran ayah terhadp remaja dengan prilaku yang menyimpang. Yoon dan kawan-kawannya melakukan analisis data sekunder dengan sampel 685 remaja berisiko yang diambil dari Studi Longitudinal tentang Pelecehan dan Kelalaian Anak. Studi ini menemukan hubungan antara anak usia dini dan pelecehan fisik dan penggunaan narkoba remaja. Ternyata ditemukan kualitas keterlibatan ayah dalam pengasuhan memberikan pengaruh pada perilaku anak-anak. Sehingga disarankan pengembangan strategi intervensi yang berfokus pada pencegahan kekerasan fisik anak usia dini dan mempromosikan hubungan ayah dan anak yang positif adalah strategi pencegahan penting untuk penggunaan narkoba remaja. Selain itu, para profesional yang bekerja dengan remaja yang berisiko harus menyadari dampak dari pelecehan fisik anak usia dini dan bertindak sesuai untuk mengurangi potensi peningkatan penggunaan narkoba remaja. ${ }^{12}$

Berbicara tentang kesehatan mental remaja dan kenakalan remaja, sebuah dilakukan terhadap 1057 remaja di kelas 7-12 dari dua sekolah yang berbeda. Hasil menunjukkan bahwa pendidikan ayah, tetapi bukan ibu, dikaitkan dengan kasih sayang remaja. Khususnya, remaja yang ayahnya berpendidikan perguruan tinggi hanya memiliki tingkat kasih sayang diri tertinggi; perbedaan signifikan ditemukan antara belas kasihan diri dari remaja dan ayah dengan gelar sarjana dan mereka yang bergelar doktor atau profesor.

Remaja dengan tingkat pendidikan ayah yang tinggi menjadi proksi untuk faktor-faktor lain seperti status sosial ekonomi, gaya pengasuhan, atau kedekatan hubungan orang tua-remaja. Artinya bahwa kasih sayang seorang ayah terhadap anak-anakanya memberikan pengaruh dalam banyak hal perkembangan psikis dan mentalnya. ${ }^{13}$ Penelitian lebih ekstrem menyorot tentang prilaku bunuh diri remaja yang diakaitkan dengan temperamen Ayah dan karakternya. Kelompok studi terdiri 117 orang tua dari 71 upaya bunuh diri remaja dan 119 orang tua dari 71 remaja usia dan jenis kelamin yang cocok tanpa upaya bunuh diri dimasukkan sebagai kelompok kontrol. Hasil penelitian menawarkan modalitas psikoterapi baru perlu mempertimbangkan sifat kepribadian orangtua yang

\footnotetext{
${ }^{11}$ Xingchao Wang, Jiping Yang, Pengcheng Wang, Li Lei, Childhood maltreatment, moral disengagement, and adolescents' cyberbullying perpetration: Fathers' and mothers' moral disengagement as moderators, Computers in Human Behavior, Volume 95, 2019, Pages 48-57, ISSN 0747-5632, https://doi.org/10.1016/j.chb.2019.01.031.

12 Susan Yoon, Fei Pei, Xiafei Wang, Dalhee Yoon, Guijin Lee, Karla Shockley McCarthy, Sarah J. Schoppe-Sullivan, Vulnerability or resilience to early substance use among adolescents at risk: The roles of maltreatment and father involvement, Child Abuse \& Neglect, Volume 86, 2018, Pages 206-216, ISSN 0145-2134, https://doi.org/10.1016/j.chiabu.2018.09.020.

${ }^{13}$ Karen Bluth, Jinyoung Park, Christine Lathren, Is parents' education level associated with adolescent self-compassion?, EXPLORE, 2020, ISSN 1550-8307, https://doi.org/10.1016/j.explore. 2020. 02.003.
} 
berisiko tinggi akan bermanfaat untuk mendukung hubungan orangtua-remaja dan mungkin memiliki efek pencegahan pada bunuh diri remaja. ${ }^{14}$

Penelitian tentang peran ayah juga dilakukan di tanah air. Penelitian ini dilakukan terhadap 166 remaja SMA dengan alat ukur yang digunakan adalah open-ended question. Pengolahan data menggunakan analisis deskriptif dengan pendekatan indigenouss. ${ }^{15}$ Hasil penelitian menemukan bahwa terdapat tiga komponen besar yang dilakukan oleh ayah dalam merawat anaknya yaitu adanya kebutuhan afeksi, Pengasuhan dan dukungan financial. Dari ketiga hal tersebut ternyata afekti dan pengasuhan lebih tinggi persentasenya dibandingkan dengan dukungan finansial. Hal ini bisa diambil kesimpulan bahwa ternyata dalam kenyataannya anak-anak lebih menginginkan perhatian, dukungan moril dan psikologis dari sosok seorang ayah serta bukan sekedar pemberian finansial saja. Selain itu penelitian lain dilakukan untuk melihat bagaimana peran ayah tetapi uniknya penelitian meneliti sosok ayah melalui perspektif ayah itu sendiri. 100 sosok ayah dilobatkan dalam penelitian ini. ${ }^{16}$ Hasil penelitian ditemukan lebih dari 85\% mereka berpendapat bahwa tugas mendidik anak adalah tugas bersama antara suami-isteri. Walaupun tugas dan tanggungjawab menafkahi keluarga adalah tanggungjawab ayah tetapi bukan bearti mendidik anak bukan tanggungjawab ayah. Penelitian ini memberikan gambaran bahwa laki-laki dewasa ini memiliki kesadaran yang tinggi akan tugas dan tanggungjawabnya sebagai sosok seorang ayah.

\section{B. Peran Ayah dalam Keluarga}

Keluarga dalam perspektif sosiologis merupakan unit terkecil yang terdiri dari suami, istri dan anak. Sedangkan dari perspektif pendidikan keluarga yaitu lembaga pendidikan yang pertama dan utama dalam kehidupan manusia. ${ }^{17}$ Dalam hal ini orang tua di samping berkewajiban untuk membesarkan anak menjadi dewasa secara fisik biologis, juga berkewajiban untuk mendewasakan secara spiskologis dan spiritual dengan memberikan nasehat yang baik, menanamkan kayakinan hidup yang benar agar anak menjadi seorang muslim yang beriman teguh bertaqwa kepada Allah SWT dan memberikan contoh nilainilai akhlakul karimah dalam kehidupan yang baik.

Keluarga menjalankan peranannya sebagai suatu sistem sosial yang dapat membentuk karakter serta moral seorang anak. Keluarga tidak hanya sebuah wadah tempat berkumpulnya ayah, ibu, dan anak. Sebuah keluarga sesungguhnya lebih dari itu. Keluarga merupakan tempat ternyaman bagi anak. Berawal dari

14 Nurullah Bolat, Tayyib Kadak, Kayi Eliacik, Enis Sargin, Secil Incekas, Hatice Gunes, Maternal and paternal personality profiles of adolescent suicide attempters, Psychiatry Research, Volume 248, 2017, Pages 77-82, ISSN 0165-1781, https://doi.org/10.1016/j.psychres.2016.12.017.

${ }^{15}$ Harmaini, H., Shofiah, V., \& Yulianti, A. (2015). Peran ayah dalam mendidik anak. Jurnal psikologi, 10(2), 80-85.

${ }^{16}$ Hidayati, F., Kaloeti, D. V. S., \& Karyono, K. (2011). Peran ayah dalam pengasuhan anak. Jurnal Psikologi, 9(1).

17 Darwis, Djamaluddin, 2010. Dinamika Pendidikan Islam: Sejarah Ragam dan Kelembagaan. RasailSemarang. 139. 
keluarga segala sesuatu berkembang. Kemampuan untuk bersosialisasi, mengaktualisasikan diri, berpendapat, hingga perilaku yang menyimpang. Ahmad Tafsir ${ }^{18}$ dalam bukunya menjelaskan bahwa kunci pendidikan dalam keluarga sebenarnya terletak pada pendidikan rohani. Ada dua tujuan pendidikan agama dalam keluarga. Pertama, penanaman nilai dalam arti pandangan hidup, yang kelak mewarnai perkembangan jasmani dan akalnya. Kedua, penanaman sikap yang kelak menjadi basis dalam menghargai guru dan pengetahuan din sekolah.

Dasar-dasar pendidikan agama dapat diberikan melalui dengan percontohan atau uswah hasanah, misalnya orang tua akan bersembahyang hendaklah anak disuruh berdiri dibelakangnya untuk menirukan perbuatan orang tuanya, pada bulan puasa anak-anak dapat dilatih berpuasa. Latihan hidup bersosial pun dapat dilakukan antara lain bila ada pengemis yang datang ke rumah hendaknya anak di suruh serahkan sesuatu pemberian kepadda pengemis tersebut $^{19}$. Latihan ibadah seperti ucapan atau perkataan, seperti membaca basmallah, mengucapkan salam, membaca dzikir dan lain-lain juga perlu menjadi kebiasaan ucapan anak-anak. Cara yang demikian telah diajarkan oleh Rasulullah dalam hadits berikut:$$
\text { الزموا أولادكم واحسنوا ادبهم }
$$ \\ "Hendaklah kamu memastikan anak-anakmu belajar agama dan hendaklah kamu membaguskan adabnya".}

Hadits diatas menyebutkan perintah kepada orangtua untuk memperhatikan pendidikan agama bagi anak. Pelajaran agama menjadi pendidikan utama yang perlu diperhatikan untuk seorang anak. Kata-kata berikutnya tersurat memperbagus adabnya. Rasulullah mempertegas tentang adab, sopan santun akhlak anak, walaupun sebenarnya dalam kata ilmu agama sudah masuk pendidikan akhlak namun untuk menunjukkan pentingnya pendidikan akhlak sehingga kata adab dikeluarkan lagi dari kata pelajaran agama. Dan ini adalah tanggungjawab orangtua. Dari mana kita mengetahui bahwa ayah memiliki tanggujawab dn berpengaruh pada akhlak seorang anak, kajian berikutnya akan menyajikan ayat-ayat al-Qur'an yang mengisahkan bagaimana peran ayah untuk anak-anaknya.

Didalam al-Quran peran ayah sebagai orang tua dalam mendidik anak lebih banyak dijelaskan di bandingkan dengan peran ibu, sebagaimana dalil-dalil berikut:

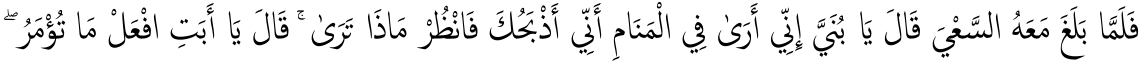

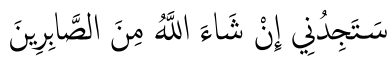

Maka tatkala anak itu sampai (pada umur sanggup) berusaba bersama-sama Ibrahim, Ibrahim berkata: "Hai anakeu Sesunggubnya aku melihat dalam mimpi

18 Tafsir, Ahmad, 2010. Ilmu Pendidikan Dalam Perspektif Islam (Bandung: PT Remaja Rosdakarya), 157.

${ }^{19}$ Masy'ari, Anwar. 1991. Membentuk Pribadi Muslim, Alma’arif- Bandung. 45 
bahwa aku menyembelihmu. Maka fikirkanlah apa pendapatmu!" ia menjawab: "Hai bapakku, kerjakanlah apa yang diperintahkan kepadamu; insya Allah kamu akan mendapatiku Termasuk orang-orang yang sabar". (QS. As-Saffat:102)

Dalam surat Luqman ayat 13-19 juga menceritakan tentang kisah Luqmanul hakim seorang tokoh pendidik, seorang bapak, orang tua yang dicontohkan dalam al-Quran dalam pendidikan keluarga.

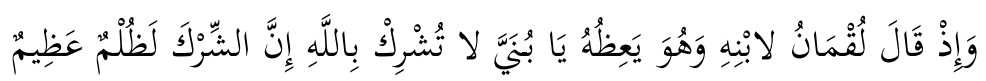

Dan (ingatlah) ketika Luqman berkata kepada anaknya, di waktu ia memberi pelajaran kepadanya: "Hai anakku, janganlah kamu mempersekutukan Allah, Sesunggubnya mempersekutukan (Allah) adalah benar-benar kezaliman yang besar".

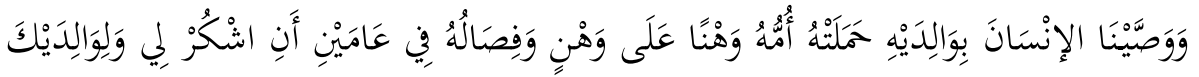

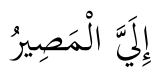

Dan Kami perintahkan kepada manusia (berbuat baik) kepada dua orang ibubapanya; ibunya telah mengandungnya dalam Keadaan lemah yang bertambahtambah, dan menyapibnya dalam dua tahun bersyukurlah kepadaku dan kepada dua orang ibu bapakmu, hanya kepada-Kulab kembalimu.

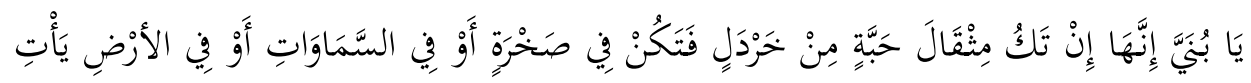

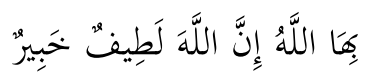

(Luqman berkata): "Hai anakeku, Sesunggubnya jika ada (sesuatu perbuatan) seberat biji sawi, dan berada dalam batu atau di langit atau di dalam bumi, niscaya Allah akan mendatangkannya (membalasinya). Sesunggubnya Allah Maba Halus [1181] lagi Maha mengetabui.

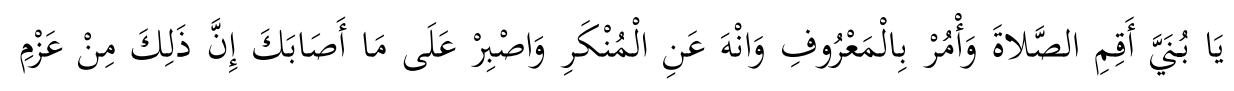

$$
\text { الأمُورِ }
$$

Hai anakku, dirikanlah shalat dan surublab (manusia) mengerjakan yang baik dan cegablah (mereka) dari perbuatan yang mungkar dan bersabarlab terbadap apa yang menimpa kamu. Sesunggubnya yang demikian itu Termasuk hal-hal yang diwajibkan (oleh Allah).

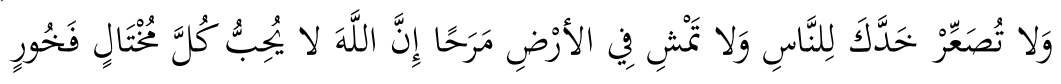

Dan janganlah kamu memalingkan mukamu dari manusia (karena sombong) dan janganlah kamu berjalan di muka bumi dengan angkuh. Sesunggubnya Allah tidak menyukai orang-orang yang sombong lagi membanggakan diri.

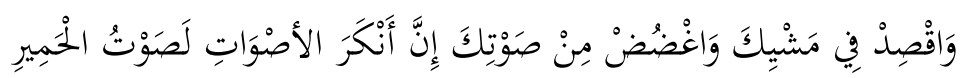

Dan sederhanalah kamu dalam berjalandan lunakkanlah suaramu. Sesunggubnya seburuk-buruk suara ialah suara keledai.

Ayat-ayat di atas secara runtun mengajarkan orangtua untuk memperhatikan apa saja yang harus diberikan kepada anak. Hal utama dimulai 
dari memberikan pendidikan aqidah atau ketahudan kepada anak yaitu berupa larangan untuk menyekutukan Allah. Sehingga dapat diketahui mengajarkan tentang keesaan Allah adalah hal utama yang perlu diberikan kepada anak-anak. Kedua adalah perintah untuk berbuat baik pada kedua orangtua. Ayat ini juga memperkuat bagaimana perjuangan ibu terhadap anak beserta kewajiban ibu untuk menyusui anak-anaknya. Ketiga, ayat di atas mengisyaratkan bahwa apabun amal manusia besar dan kecil semuanya tidak luput dari pengawasan Allah. Sehingga hal ini juga perlu disampaikan kepada anak bahwa sekecil apapun amalannya diketahui dan dicatat serta akan dipertanggungjawabkan. Keempat, berisi perintah untuk shalat dan juga perintah untuk sabar. Kesabaran sendiri dalam psikilogi masuk dalam wilayah karakter yang didiskusikan kemudian dalam psikologi positif. Kelima, adalah larangan untuk tidak menjadi orang yang sombong, artinya anak-anak diajarkan untuk menjadi insan yang rendah hati dan tidak anggkuh. Keenam adalah penegasan dari akhlakul karimah yaitu bicara dengan lembut dengan suara yang baik dan tidak menyakiti perasaan orang lain.

Richard C. Halverson ${ }^{20}$ juga berpendapat bahwa ayah bertanggung jawab atas tiga tugas utama. Pertama, ayah haruslah mengajar anaknya tentang Tuhan dan mendidik anaknya dalam ajaran agama. Kedua, seorang ayah haruslah mengambil peran sebagai pimpinan dalam keluarganya. Ketiga, ayah haruslah bertanggung jawab atas disiplin. Dengan demikian ia menjadi seorang figur otorita. Karena begitu besarnya tanggung jawab orang tua dan begitu dekatnya hubungan orang tua dengan anak-anaknya, maka Nabi Muhammad Saw bersabda bahwa ridha Allah dan keberkahan Allah itu sangat tergantung pada keridhaan orang tua.

\section{Pembentukan Karakter Anak}

Karakter berasal dari bahasa latin "charassein", "kharax" dalam bahasa Inggris "character". Menurut Ratna Megawangi, ${ }^{21}$ "sebuah usaha untuk mendidik anak-anak agar dapat mengambil keputusan dengan bijak dan mempraktikkan dalam kehidupan sehari-hari, sehingga mereka dapat memberikab kontribusi yang positif kepada lingkungannya. Sedangkan menurut definisi lain dikemukakan oleh Fakry Gaffar ${ }^{22}$ sebuah proses transformasi nilai-nilai kehidupan untuk ditumbuhkembangkan dalam kepribadian seseorang sehingga menjadi satu dalam perilaku kehidupan orang itu.

Prasetyo berpendapat bahwa proses pembentukan karakter pada anak ibarat mengukir atau memahat jiwa sedemikian rupa, sehingga "berbentuk" unik, menarik, dan berbeda antara satu dengan yang lain. Dengan demikian, dalam pendidikan karakter, setiap anak memiliki potensi untuk berperilaku positif atau negatif. Jika ibu dan ayah membentuk karakter positif sejak anak usia

${ }^{20}$ Richard C. Halverson (2002), "What G o d Expects from Fathers" dalam Parents \& Children.

${ }^{21}$ Megawangi, Ratna. 2004. Pendidikan Karakter, Solusi Yang Tepat untuk Membangun Bangsa. Bogor: Indonesia Heritage Foundation. 95

${ }^{22}$ Gaffar, Mohammad Fakry. 2010. Pendidikan Karakter Berbasis Islam. (Disampaikan pada Workshop Pendidikan Karakter Berbasis Agama, 08-10 April 2010 di Yogyakarta) 
dini, maka yang berkembang adalah perilaku positif tersebut. Jika tidak, tentu yang akan terjadi sebaliknya.

Nilai-nilai karakter yang dapat diterapkan oleh orang tua dalam lingkungan keluarga adalah nilai religius, jujur, bertanggungjawab, percaya diri, saling menghormati, menggunakan tutur bahasa yang baik, sopan, santun, komunikatif, disiplin, kreatif, peduli terhadap keluarga, mandiri, toleransi, pemaaf, ramah, sikap hormat, rasa memiliki, sabar, dan sportif. Prasetyo juga berpendapat bahwa proses pembentukan karakter diawali dengan kondisi pribadi ibu-ayah sebagai figur yang berpengaruh untuk menjadi panutan, keteladanan, dan diidolakan atau ditiru anakanak. Anak lebih mudah meniru perilaku dari pada menuruti nasihat yang diberikan ibu-ayahnya. Mereka belajar melalui mengamati apa yang ada dan terjadi di sekitarnya, bukan lewat nasihat semata-mata. Nilai yang diajarkan melalui kata kata, hanya sedikit yang akan mereka lakukan, sedangkan nilai yang diajarkan melalui perbuatan, akan banyak mereka lakukan. Sikap dan perilaku ibu-ayah sehari-hari merupakan pendidikan watak yang terjadi secara berkelanjutan, terus menerus dalam perjalanan umur anak.

Proses selanjutnya adalah memberikan pemahaman dan contoh perilaku kepada anak tentang baik dan buruk, benar atau salah, mana yang boleh dan tidak boleh dilakukan. Anak juga perlu diajarkan untuk dapat memilah dan memilih sesuatu yang baik, sehingga ia bisa mengerti tindakan apa yang harus diambil, serta mampu mengutamakan hal-hal positif untuk dirinya. Untuk itu diperlukan suasana pendidikan yang menganut prinsip 3A, yaikni asih (kasih), asah (memahirkan), dan asuh (bimbingan). Anak akan tumbuh dan berkembang dengan baik kalau mendapatkan perlakuan kasih sayang, pengasuhan yang penuh pengertian, serta dalam situasi yang dirasakan nyaman dan damai.

Al-Qur'an dan Hadits Nabi berbicara tentang karakter atau dalam bahasa agama disebut dengan akhlak. Akhlak merupakan istilah dalam bahasa arab yang merujuk pada praktik-praktik kebaikan, moralitas dan perilaku yang baik. Istilah akhlak sering diterjemahkan dengan perilaku islami, sifat atau watak, perilaku baik, kodrat atau sifat dasar, perangai, etika atau tata susila, moral dan karakter. Semua kata tersebut merujuk pada kata karakter yang dapat dijadikan suri tauladan yang baik bagi orang lain. Di sinilah yang dimaksudkan Allah dalam al-Qur'an surat Al Ahzab ayat 21:

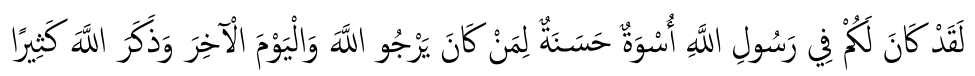
Sesungguhnya telah ada pada (diri) Rasulullah itu suri teladan yang baik bagimu (yaitu) bagi orang yang mengharap (rahmat) Allah dan (kedatangan) hari kiamat dan Dia banyak menyebut Allah.

Ayat tersebut memberi gambaran betapa Rasulullah merupakan suri tauladan dalam berbagai hal karena memiliki sifat, perangai, watak, dan moralitas yang patut dicontoh dan dijadikan model dalam berpikir, bersikap dan 
bertindak. Perbaiki budi pekerti, perangai sifat atau karakter merupakan tanggungjawab semua pihak apalagi dengan gelar "khalifah di bumi yang disandang oleh semua hamba yang artinya berlaku dan bertindak sesuai dengan budi pekerti yang agung, sebagaimana yang diamanahkan oleh Allah dalam Al Qur'an surat al Qalam ayat 4 berikut ini:

Artinya: dan Sesunggubnya kamu benar-benar berbudi pekerti yang agung.

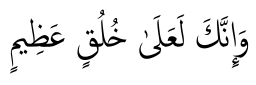

Mengingat dalam diri Rasulullah Muhammad Saw terdapat suri tauladan yang baik dan berbudi pekerti luhur, maka kata wainnaka (sesungguhnya kamu) dalam ayat ini merujuk kepada Rasulullah dan juga kepada siapa saja yang menjadikan dia sebagai teladan serta bertindak sesuai akhlaknya. ${ }^{23}$ Metode modelling yang sekarang marak dijadikan sebagai sebuah metode handal dalam pendidikan karakter sebenarnya telah lama dipraktekkan oleh Rasullullah. Sehingga metode ini benar-benar menjadi metode utama dalam pendidikan akhlak seorang anak. Selanjutnya berbicara tentang karakter yang diturunkan dari orangtua dalam hal ini ayah merupakan kewajiban yang dapat dilakukan melalui metode ini. Sejak kecil seorang anak akan melihat, mendengar dan merasakan bagaimana mereka diperlakukan bagaimana sosok orangtuanya bertindak bertutur kata. Semua itu terekam dan menjadi karakter mereka secara langsung. Sehingga jika berharap anak menjadi shaleh dan shalehah maka akhlak itu harus terlebih dahulu melekat pada orangtua, seperti halnya Rasulullah dalam mendidik anakanaknya dengan suri tauladan yang yang mulia.

\section{Catatan Akhir}

Pembentukan karakter pada anak ibarat mengukir atau memahat jiwa sedemikian rupa, sehingga "berbentuk" unik, menarik, dan berbeda antara satu dengan yang lain. Dari sini kemudian berkembang pengertian karakter yang diartikan sebagai pendidikan untuk membentuk kepribadian seseorang melalui pendidikan budi pekerti yang hasilnya terlihat dalam tindakan nyata seseorang, yaitu tingkah laku yang baik, jujur, bertanggungjawab, menghormati hak orang lain, kerja keras, dan sebagainya. Orangtua harus menanamkan karakteristik pada masing-masing anak sejak ia dilahirkan ke dunia ini.

Pembentukan karakter merupakan perilaku yang didapat dari pola asuh yang dilakukan terus menerus dan berkesinambungan. Oleh karena itu anak adalah peniru ulung, maka orang tua harus memberikan contoh karakter yang baik pula terhadap anakanaknya. Dari uraian teks dan konteks di atas dapat dengan jelas terlihat bahwa ayah adalah sosok yang sangat berpengaruh pada pembentukan karakter anak. Secara normatif ayat-ayat al-Qur'an mengisahkan bagaimana seharusnya seorang ayang bertindak terhadap anak dan dilapangan dari hasil penelitian para ahli pun ditemukan kenyataan-kenyataan yng menakjubkan. Temuan-temuan dalam penelitian bukan saja memberikan pelajaran bagaimana posisi ayah dalam banyak sisi kehidupan anak ia

${ }^{23}$ Hamdani, Hamid dkk, 2013. Pendidikan Karakter Perspektif Islam, Pustaka Setia, Bandung. 6 
berperan, tetapi temuan-temuan kontekstual tersebut ikut membuktikan bahwa konsep pendidikan anak oleh orangtua khususnya ayah tidak bisa dinafikan kebenarannya, dan tidak pula dilampaui masa dan zaman karena al-Qur'an tetap akan sesuai di sepanjang zaman kehidupan manusai.

\section{Daftar Rujukan}

Adnan Hasan Salih Baharits, Tanggung Jawab Ayah terhadap Anak Laki-laki, Jakarta: Gema Insani Press, 1996), 29

April Litchford, Mateja R. Savoie Roskos, Heidi Wengreen, Influence of fathers on the feeding practices and behaviors of children: A systematic review, Appetite, Volume 147, 2020, 104558, ISSN 0195-6663, https://doi.org/10.1016/j.appet.2019.104558.

B. Barker, J.E. Iles, P.G. RamchandaniFathers, fathering and child psychopathology Curr. Opin. Psychol., 15 (2017), pp. 87-92

Basel El-Khodary, Muthanna Samara, The mediating role of trait emotional intelligence, prosocial behaviour, parental support and parental psychological control on the relationship between war trauma, and PTSD and depression, Journal of Research in Personality,Volume 81, 2019,

Charles Opondo, Maggie Redshaw, Maria A. Quigley, Association between father involvement and attitudes in early child-rearing and depressive symptoms in the pre-adolescent period in a UK birth cohort, Journal of Affective Disorders, Volume 221, 2017, Pages 115-122, ISSN 0165-0327, https://doi.org/10.1016/j.jad.2017.06.010.

Darwis, Djamaluddin, 2010. Dinamika Pendidikan Islam: Sejarah Ragam dan Kelembagaan. Rasail- Semarang.

Gaffar, Mohammad Fakry. 2010. Pendidikan Karakter Berbasis Islam. (Disampaikan pada Workshop Pendidikan Karakter Berbasis Agama, 08-10 April 2010 di Yogyakarta)

Hamdani, Hamid dkk, 2013. Pendidikan Karakter Perspektif Islam, Pustaka Setia, Bandung. Harmaini, dkk. 2014. Peran Ayah Dalam Mendidik Anak, Jurnal Psikologi, Volume 10 Nomor 2, Desember 2014, Center for Indigenous Psychology, Riau.

Harmaini, H., Shofiah, V., \& Yulianti, A. (2015). Peran ayah dalam mendidik anak. Jurnal psikologi, 10(2), 80-85.

Hidayati, F., Kaloeti, D. V. S., \& Karyono, K. (2011). Peran ayah dalam pengasuhan anak. Jurnal Psikologi, 9(1).

Holly A. Harris, Elena Jansen, Tony Rossi, 'It's not worth the fight': Fathers' perceptions of family mealtime interactions, feeding practices and child eating behaviours, Appetite, Volume 150, 2020,104642, ISSN 0195-6663, https://doi.org/10.1016/j.appet.2020.104642.

ISSN 0747-5632, https://doi.org/10.1016/j.chb.2019.01.031.

Jaimie L. O'Gara, Anao Zhang, Yolanda Padilla, Chun Liu, Kaipeng Wang, Fatheryouth closeness and adolescent self-rated health: The mediating role of mental health, Children and Youth Services Review, Volume 104, 2019, 104386, ISSN 0190-7409, https://doi.org/10.1016/j.childyouth.2019.104386.

Ji-Hye Hwang, Sun-Mi Chae, Experiences of fathers of young children with severe congenital heart efects in Korea: A qualitative descriptive study, Journal of Pediatric Nursing, 2020, ISSN 0882-5963, https://doi.org/10.1016/j.pedn.2020.02.040. 
Karen Bluth, Jinyoung Park, Christine Lathren, Is parents' education level associated with adolescent self-compassion?, EXPLORE, 2020, ISSN 1550-8307, https://doi.org/10.1016/j.explore.2020.02.003.

Keusuma, dkk, 2011. pendidikan karakter kajian teori dan praktek di sekolah, PT Remaja Rosdakarya- Bandung.

Masy'ari, Anwar. 1991. Membentuk Pribadi Muslim, Alma'arif- Bandung.

Maternal and paternal personality profiles of adolescent suicide attempters, Psychiatry Research, Volume 248, 2017, Pages 77-82, ISSN 0165-1781, https://doi.org/10.1016/j.psychres.2016.12.017.

Megawangi, Ratna. 2004. Pendidikan Karakter, Solusi Yang Tepat untuk Membangun Bangsa. Bogor: Indonesia Heritage Foundation.

N.J. Cabrera, H.E. Fitzgerald, R.H. Bradley, L. RoggmanThe ecology of father-child elationships: an expanded model J. Fam. Theory Rev., 6 (4) (2014), pp. 336-354

Nurullah Bolat, Tayyib Kadak, Kayi Eliacik, Enis Sargin, Secil Incekas, Hatice Gunes,

Pages 246-256, ISSN 0092-6566, https://doi.org/10.1016/j.jrp.2019.06.004.

Pamella H. Oliver, Diana Wright Guerin, Jacqueline K. Coffman, Big five parental personality traits, parenting behaviors, and adolescent behavior problems: A mediation model, Personality and Individual Differences, Volume 47, Issue 6, 2009, Pages 631-636, ISSN 0191-8869, https://doi.org/10.1016/j.paid.2009.05.026.

Prasetyo, Nana, 2010. Membangun Karater Anak Usia Dini, Direktorat Pembinaan Pendidikan Anak Usia DiniDirektorat Jenderal Pendidikan Anak Usia Dini Nonformal dan Informal Kementerian Pendidikan Nasional.

Qiana R. Cryer-Coupet, Marquitta S. Dorsey, Brianna P. Lemmons, Elan C. Hope, Examining multiple dimensions of father involvement as predictors of risktaking intentions among black adolescent females, Children and Youth Services Review, Volume 108, 2020, 104604, ISSN 0190-7409, https://doi.org/10.1016/j.childyouth.2019.104604.

R. Kok, P. Prinzie, M.J. Bakermans-Kranenburg, F.C. Verhulst, T. White, H. Tiemeier, et al.Socialization of prosocial behavior: gender differences in the mediating role of child brain volume Child Neuropsychol., 18 (10) (2018), pp. 1-11

Richard C. Halverson (2002), "What G o d Expects from Fathers" dalam Parents \& Children.

Susan Yoon, Fei Pei, Xiafei Wang, Dalhee Yoon, Guijin Lee, Karla Shockley McCarthy, Sarah J. Schoppe-Sullivan, Vulnerability or resilience to early substance use among adolescents at risk: The roles of maltreatment and father involvement, Child Abuse \& Neglect, Volume 86, 2018, Pages 206-216, ISSN 0145-2134, https://doi.org/10.1016/j.chiabu.2018.09.020.

Tafsir, Ahmad, 2010. Ilmu Pendidikan Dalam Perspektif Islam, PT Remaja RosdakaryaBandung.

V. Sethna, E. Perry, J. Domoney, J. Iles, L. Psychogiou, N.E.L. Rowbotham, et al.Father-child interactions at 3 months and 24 months: contributions to children's cognitive development at 24 months Infant Ment. Health J., 38 (3) (2017), pp. 378-390

Vaheshta Sethna, Jasmine Siew, Inês Pote, Siying Wang, Maria Gudbrandsen, Charlotte Lee, Emily Perry, Kerrie P.H. Adams, Clare Watson, Johanna Kangas, Vladimira Stoencheva, Eileen Daly, Maria Kuklisova-Murgasova, Steven C.R. Williams, Michael C. Craig, Declan G.M. Murphy, Grainne M. McAlonan,Father-infant interactions and infant regional brain volumes: A cross-sectional MRI study, 
Developmental Cognitive Neuroscience, Volume 40, 2019, 100721,ISSN 18789293, https://doi.org/10.1016/j.dcn.2019.100721

Xingchao Wang, Jiping Yang, Pengcheng Wang, Li Lei, Childhood maltreatment, moral disengagement, and adolescents' cyberbullying perpetration: Fathers' and mothers' moral disengagement as moderators, Computers in Human Behavior, Volume 95, 2019, Pages 48-57, 